\title{
Tongue cancer and pregnancy: Report of two cases in association with HPV infection and literature review. Is HPV vaccination necessary to prevent of tongue cancer?
}

Panagiotis Tsikouras $^{1 *}$, Konstantinos Paraskevopoulos ${ }^{2}$, Anastasia Bothou ${ }^{1}$, Nikoletta Pastelli ${ }^{3}$, Xanthoula Anthoulaki ${ }^{1}$, Anna Chalkidou ${ }^{1}$, Spyridon Michalopoulos ${ }^{1}$, Ioannis Tsirkas ${ }^{1}$, Fotini Gaitatzi ${ }^{1}$, Michael Koutsogiannis ${ }^{1}$, Stavroglou Athanasia ${ }^{2}$, Panagiotis Petsidis ${ }^{4}$, Stefanos Zervvoudis $^{4}$, Nikolaos Nikolettos ${ }^{1}$ and Konstantinos Vahtsevanos ${ }^{2}$

${ }^{1}$ Department of Obstetrics and Gynecology, Democritus University of Thrace, Greece

${ }^{2}$ Department of Oral and Maxillofacial Surgery, Papanikolaou General Hospital, Aristotle University of Thessaloniki Thessaloniki, Greece

${ }^{3}$ Department of Pathology, General Hospital of Thessaloniki “G. Papanikolaou”, Thessaloníki, Greece

${ }^{4}$ Department of Obstetrics and Gynecology, Rea Hospital, 17564 Athens, Greece

\begin{abstract}
The detailed research for more information on the very important area of tongue cancer is the purpose of the present study. We report two cases of pregnant women suffering from tongue cancer during pregnancy, the treatment of tongue cancer and information on the outcome of pregnancy. Pregnancy should not be considered an obstacle to the proper treatment of a mother's tongue malignancy. The epidemiological trend in recent years is to increase the overall survival of patients and keep them free of disease for a longer period of time. The reported pregnant women were in the third trimester of pregnancy with tongue cancer symptoms at 37 and 32 weeks, respectively. After detailed information, the cesarean section was performed and the two women treated according to the proposed protocols which were as following: surgical removal of tumors, lymph node dissection in 5 levels and postoperative radiotherapy. The first case of these recurred 3 months later, underwent surgical removal of the tumor and subsequently underwent chemotherapy and immunotherapy. She died one year after the primary diagnosis of tongue cancer. The perinatal effect was perfect in both cases. The lack of systematic randomized prospective studies and the difficulties in carrying them out in general, make bibliographic review even more useful in guidelines, retrospective studies, series of events and individual cases for future scientific studies to be performed in order to establish treatment protocols.
\end{abstract}

\section{Introduction}

The diagnosis of pregnancy cancer in developed countries occurs with a frequency of 1: 1000 pregnancies and complicates 0.07 to $0.1 \%$ of all pregnancies [1,2]. Cancer during pregnancy is rare and due to the rarity not a lot of research has been done. One in 118 pregnant women in the early stages of cancer is pregnant [1,2]. The most common cancers during pregnancy are those with the highest impact during the reproductive period such as breast and cervical neoplasms, hematological malignancies, cancers of the colon, ovarian and melanoma $[3,4]$. The most commonly reported rates of cancer during pregnancy are breast cancer in a percentage of $46 \%$, hematological cancers in a percentage of $18 \%$ and oral cancers with a frequency of less than $2 \%[3,4]$. In particular, cancers of the oral cavity during pregnancy include cancer of the larynx, thyroid, melanoma and lymphoma with a frequency twice as high in men as in women. The number of women diagnosed with cancer during pregnancy increase because more women have their first child in an advanced age and the risk of developing most cancers increases with age $[3,4]$. This coexistence has become more common in recent decades, and there is likely to be an upward trend due to delayed pregnancies in later reproductive years with recent references in the literature between 28 and 44 years, especially in the white race. In the last years is observed an increasing frequency of the cancer disease in younger patients and occurred not mainly in the older population as in the past. The first report concerning to tongue cancer in the pregnancy was referred in 1958 and the ten references from this time were associated to high mortality, approximately in 36\% [1]. Tongue cancer is the most common cancer from the oral cancers, however is less associated to conventional risk factors. According to scientists, this cancer is the most dangerous of the approximately 1,000 diseases that occur in the oral cavity [5-7]. The main reasons for the annual increase in tongue cancer worldwide and in Greece, are: smoking, alcohol consumption and possibly HPV viruses [5-7]. Studies have shown that from $7 \%$ of people who have oral HPV, only $1 \%$ have HPV type 16 subtype which is responsible for oral cancer. Oral cancer related to HPV is about three times more common in men than in women. HPV is mainly responsible for cancers in the back of the mouth (in the tonsils, at the base of the tongue [8]. Tongue-based cancer is the second most common cancer in Sweden after tonsillitis and is more common in Latin American countries than in northern European countries. This difference is due to the fact that the oral mucosa at the back is different from the anterior one and facilitates the entry of the virus into

*Correspondence to: Panagiotis Tsikouras, Professor Department Obstetrics and Gynecology, Democritus University of Thrace, Greece, E-mail: ptsikour@med.duth.gr

Key words: tongue cancer, pregnancy, management

Received: June 29, 2020; Accepted: July 17, 2020; Published: July 20, 2020 

prevent of tongue cancer?

the basal layer of the epithelium. Although some reports in the past described tongue carcinomas in association to pregnancy, however is not concluded final etiological explanation. According to some authors, the reasons for this mentioned association are as following: high levels of estrogen and testosterone during the first 20 weeks of pregnancy and immunosuppression in the same period which due to the down regulation of classical HLA -G antigens led to TH2 (Tumor growth promotor) cytokine activity and block antibodies, which induce in the immunocytes the apoptosis [1,7]. Controversially during pregnancy Th1 cytokine activity is suppressed which means the antitumor activity is moderate declined, however has no notable effect to prognosis [1,7]. The suppression of the immune system based on hormones mainly in corticosteroids, human horionic gonadotropin, which affect to reduce number of T lymphocytes, CD8+ Cells, in the blood circulation and their activity to mitogens $[1,7]$. Although there are not confirm the main female hormonal receptors estrogen and progesteron in the head and neck tissues depending on the immunosuppression in the first half of pregnancy could be predispose to occur malignant tumor independent to hormonal status.

Tongue neoplasia in pregnancy now involves two organisms and both the diagnostic approach and the therapeutic approach should be balanced to find suitable option of treatment of the tumor without risk for the fetus or continued pregnancy and her final outcome $[9,10]$.

Diagnostic and therapeutic radiation required careful application, while systemic chemotherapy is not allowed during the first trimester of pregnancy due to fetal or teratogenic effects, as well as congenital malformations [11-14].

The decisions are very difficult for the surgeons, which deal with cancers in the oral facial maxillar area due to the rarity appearance of the cancers, not existing general guidelines and occurrence of ethical emotional dilemmas related to pregnant woman, fetus, her husband by recommended of the suitable management $[15,16]$. In the present study, after describing our cases, we reviewing the association of the tongue cancer during pregnancy based on the available literature, which recommend treatment options are available, the correct knowledge of which may contribute to ensuring maximum of the best health of the mother and the best perinatal result. The recommend available treatment protocols are independent from pregnancy.

\section{First case report}

A carcinoma of the tongue presented in a woman 38 years old, II Gravida, I Para late in the third trimester, in the 37 week of pregnancy. The pregnant woman was mother of a4-yeat old child. Her medical history was clear and had no family history of cancer. She had smoked 20 cigarettes a day from her puberty years until beginning the second pregnancy. She was referred to the Ambulance of Department Oral and Maxillofacial Surgery of Papanikolaou Hospital Thessaloniki complaining of focal hardness left lateral part of tongue. Her physical examination in oral cavity was notable and found a white lesion in the left lateral tongue with palpable induration extending across lateral line approaching to midline, which was occasionally painful, associated to pain in the left ear.

MRI (Magnetic Resonance Imaging) examination was preoperatively performedon a $0.2 \mathrm{~T}$ GE SIGNA MRI scanner. Pulse sequences T1-WI, T2-WI and STIR confirmed malignant neoplasm of the oral cavity which within the limits of the discretion of MRI $0.2 \mathrm{~T}$ was not recognized. An elongated lymph node morphology $11 \mathrm{~mm}$ in diameter in the left submandibular region and numerous suspicious lymph nodes along the vascular bundle of amphorae less than 10 $\mathrm{mm}$ were identified. The termination of pregnancy was discussed. The pregnancy was continued normally and in collaboration with her obstetrician she delivered in the $38^{\text {th }}$ week of pregnancy by elective cesarean section, a healthy male infant weighing 2750 gr. Preoperatively was administrated by obstetricians betamethasone steroid prophylaxis intramuscular 24 hours before the cesarean section and 4500 anti Xa 0.45 tinzzeparin sodium postoperatively for 7 days. This mentioned pregnant woman was underwent transoral excision of the left lateral posterior part of the tongue together with the surround tissue with at least $1 \mathrm{~cm}$ around the lesion and a deep of $0.6 \mathrm{~cm}$. Selective neck dissection included removal of lymph nodes from levels I to IV Level I: submental and submandibular, Level II: superior spinal accessory, superior jugular, jugulo digastric, Level III: Midjugular, Level IV: Jugulo omohyoid, Inferior jugular Level V:Inferior spinal accessory, Transverse cervical.

The pathological specimen revealed findings compatible with nonkeratinized squamous cell carcinoma. Clinical staging of the tumour was $\mathrm{T}_{1} \mathrm{~N}_{0} \mathrm{M}_{\mathrm{X}}-\mathrm{SCCG}_{2} / \mathrm{XXEE} / \mathrm{LN}: 0 / 24$ moderate differentiation, with a depth of infiltration maximum diameter $0.6 \mathrm{~cm}$, involved the left margin of the tongue, however negative tumor margins. Perineuric infiltrates are observed, without obvious neoplastic invasion in lymph vessels administrated by the obstetricians. Immunhistochemical examination was positive to 63 , Ck 5/6, S-100, CD 34, Ki-67. No cervical lymph node metastasis was confirmed. Blood units transfusion was not necessary. The blood loss was $380 \mathrm{ml}$, the duration of the surgery was 4 hours and 35 minutes and after that the patient was transferred in intensive care unit for 24 hours. The postoperative course was without any complication, dysfunction of tongue or reduction of life quality. Moreover, the postoperative pain control consisted of administration by morphine derivate with the usage of a self-controlled analgetic pump. She went home 10 days after surgery with satisfactory speech and swallowing. She received $65 \mathrm{~Gy}$ of external radiation to tumour bed and right upper cervical region. She was followed -up regularly in an outpatient clinic, however three months later suspicion of recurrence occurred in tongue left area ulcerative lesion black color.

MRI and positron emission tomography (PET -CT) confirmed recurrence of primary diagnosed tongue cancer three months after the first diagnosis. The test was performed on a Philips Intera 1.5T Magnetic Resonance Imaging System and PET - CT had the following aspects: In the native muscles of the tongue to the left of the midline, in the boundary between the base and finally, the apex of the sublingual adipose layer of the corresponding lingual vessels. An area of pathological lesion of about 15X11X18 mm suspected malignancy, possible infiltrated lymph node the possibility of infiltration cannot be ruled out.

The patient underwent in tumorectomy. The histological examination revealed the following result: The cells have deep-colored uneven nuclei, with several nuclei and eosinophilic cytoplasm. Focal intercellular bridges, extracellular and intracellular keratinization elements, as well as keratin spheres are recognized. Between them are observed septal fibroblastic layer with focal inflammatory infiltrates. Perineural infiltrates are observed, while neoplastic cells extend to the interlocking striated muscle fibers. Focal processing reaches the excision limits of the tissue. Squamous cell carcinoma, moderate-low differentiation in the present material. From the biopsy: SCC G3 with many a typicals, frequent mitoses, infiltration of nerves, muscles, blood vessel wall, depth infiltration diameter $8 \mathrm{~mm}$, XXE proximal surgical resection limits are free of neoplastic infiltrates, but in a narrow band 
Tsikouras P (2020) Tongue cancer and pregnancy: Report of two cases in association with HPV infection and literature review. Is HPV vaccination necessary to prevent of tongue cancer?

of healthy tissues: distance plasma elements from the nearest lateral surgical resection limit of $4 \mathrm{~mm}$, distance of neoplastic speakers from the $3 \mathrm{~mm}$ depth surgical depth (Figure 1). Hypermetabolic foci in contact with surgical material superior sphincteric left on suspicion of suspected malignancy, possible infiltrated lymph node.

The tumor specimen was positive for HPV 16 subtype, confirmed after assessment by PCR mass spectrometry assay also p16 ${ }^{\text {INK4a }}$ expression, which is a sensitive surrogate marker for transcription activity of HPV high risk subtypes (Figure 2). Postoperatively the recurrence procedure was completed with chemotherapy concerning standard protocols (Figure 3). She has received four doses of systemic chemotherapy (taxotere $100 \mathrm{mg}$, cisplatin $100 \mathrm{mg}$, 5-fluorouuracil $1000 \mathrm{mg}$ ) and immunotherapy one dosis (Interferon a (IFN A) and
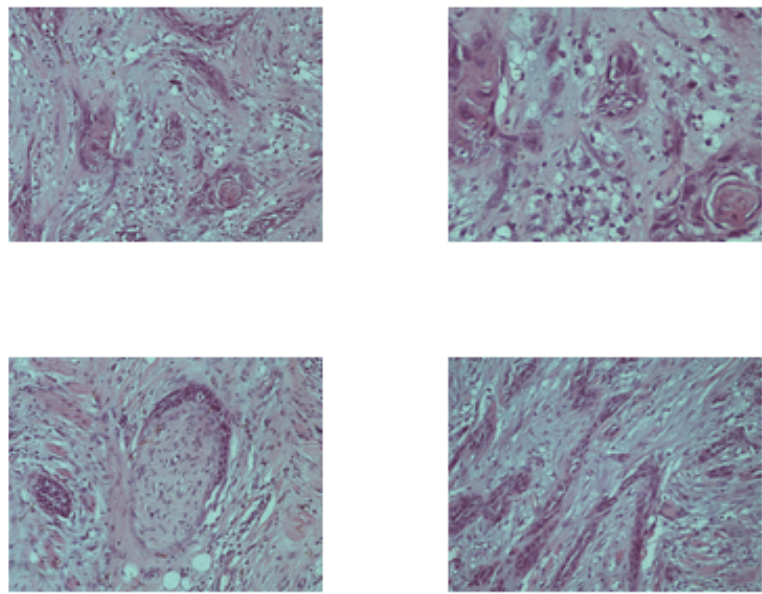

Figure 1. Expression of P16 protein in the squamous cell carcinoma
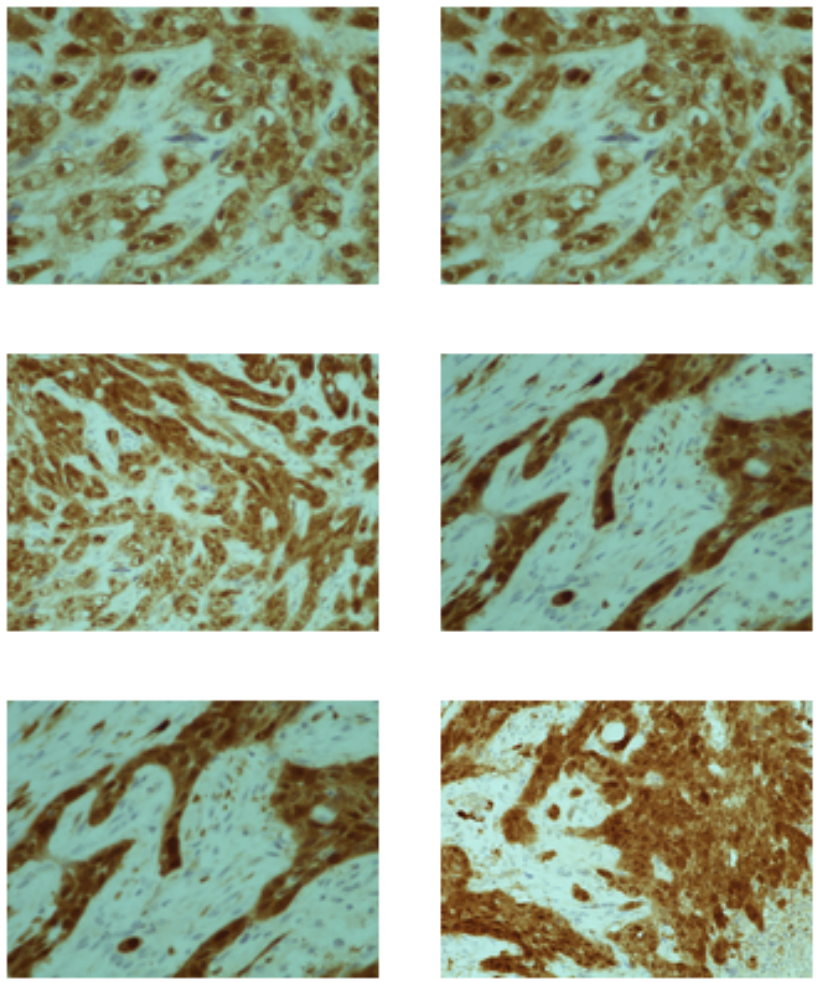

Figure 2. Squamous cell carcinoma, islands of tumour cells invading the underlying stroma

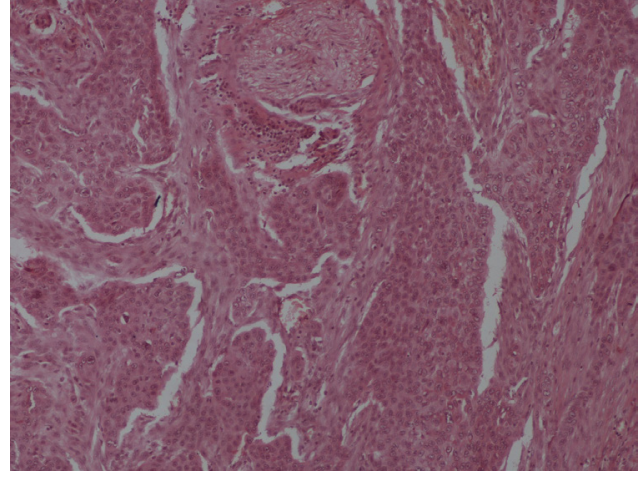

Figure 3. Squamous cell carcinoma. Perineural invasion Squamous cell carcinoma. Immature cells with numerous and atypical mitoses

Interleukin 2 (IL-2).) She died due disease progress distant metastases relapsed in the lung and in mediastinal nodes six months after the recurrence treatment and one year after the initial therapy.

\section{Second case report}

A 28 years old female patient, I Gravida, O Para, presented in the 32 week of pregnancy in our outpatient exanimated rooms complaining for pain on the tongue, moderate dysphagia and right sided pain of ear. The physical examination revealed invasion deeply into the muscle of tongue, enlarging and non-healing ulcer on her right side in the tongue basis. It was suspected by the inspection and palpation due to the occurrence and tenderness to be a cancer. Her medical history was unremarkable, except hashimoto thyreoidits disease from school years. The pregnancy continued normally until her visiting in our clinic. No family history of cancer was reported, no history of alcohol consumption but she smoked 2 pack cigarettes per day from her puberty years until the beginning of the pregnancy. Her general condition was gradually worsened and was related to the improving of pain and breath. The possibility of elective termination of pregnancy was discussed, accepted by the parents and was performed via elective cesarean section in the $34^{\text {th }}$ week of pregnancy. The pregnant woman decided to give birth earlier because the expected risks of the disease associated with pregnancy could lead to a possible risk for the fetus. She delivered a healthy female infant weighing 2380 gr by elective cesarean section after previously administration of betamethasone steroid prophylaxis two doses intramuscular 24 hours before the operation and 4500 anti Xa 0.45 tinzzeparin sodium postoperatively for 7 days by obstetrician. Immediately was performed MRI with the following findings:

During the examination presented a lesion, which occupies the right side of the tongue and appears to be attached to the maxillary muscle on the right without however showing obvious pathological infiltration in the muscle, with a total estimated size of $3.3 \times 2 \mathrm{~cm}$ in transverse Level and head length, the infiltration thickness was $0.9 \mathrm{~cm}$.

The infiltration of the bony structures of the jaw was not shown, and the infiltration of the medial pterygoid muscle was not confirmed.

The presence of a pathologically swollen cervical lymph node on the back of the submandibular salivary gland with dimensions of $12 \times 10 \mathrm{~mm}$ (Level II) is checked. A swollen right submandibular lymph node measuring $9 \times 6 \mathrm{~mm}$ is also checked.

The mentioned pregnant woman was underwent transoral excision of the right lateral posterior part of the tongue together with the surround tissue with at least $1 \mathrm{~cm}$ around the lesion and a deep 

prevent of tongue cancer?

of $1.9 \mathrm{~cm}$. Selective neck dissection included removal of lymph nodes from levels I to IV, Level I: submental and submandibular, Level II: superior spinal accessory, superior jugular, jugulo digastric, Level III: Midjugular, Level IV: Jugulo omohyoid, Inferior jugular Level V: Inferior spinal accessory, Transverse cervical.

The pathological examination revealed findings compatible with non-keratinized squamous cell carcinoma. Clinical staging of the tumour was $\mathrm{T}_{4} \mathrm{aN}_{0} \mathrm{M}_{\mathrm{X}}-\mathrm{SCC} / \mathrm{G} 2 / \mathrm{XXEE} /$, diameter: $2 \mathrm{~cm} / \mathrm{LN}: 0 / 49$ moderate differentiation, which appeared close to a lateral surgical resection of the excision border, with a depth of infiltration with maximum diameter $1.4 \mathrm{~cm}$. Perineuric infiltrates are observed, without obvious neoplastic invasion in lymph vessels (Figure 4).

Immunhistochemical examination was positive to 63 , Ck 5/6, S-100, CD 34, Ki-67. No cervical lymph node metastasis was confirmed. Blood units transfusion was not necessary. Blood loss was $250 \mathrm{ml}$ and the duration of the surgery was 5 hours and 35 minutes. After that, the patient was transferred in the intensive care unit for 24 hours. The postoperative course was without any complication, dysfunction of tongue or reduction of life quality. The postoperative pain control consisted of administration by morphine derivate through a selfcontrolled analgetic pump. She went home 10 days after surgery with satisfactory oral function. Postoperatively the recurrence procedure received four doses of systemic chemotherapy (taxotere $100 \mathrm{mg}$, cisplatin $100 \mathrm{mg}$, 5-fluorouuracil $1000 \mathrm{mg}$ ) and radiotherapy 64,4 Gy in 29 radiotherapy sessions. The tumor specimen was positive for HPV 16 subtype, confirmed after assessment by PCR mass spectrometry assay also p16 ${ }^{\mathrm{INK} 4 \mathrm{a}}$ expression which is a sensitive surrogate marker for transcription activity of HPV high risk subtypes.

\section{Discussion}

During the past four decades, tongue squamous cell carcinoma was a predominant disease in males, with only a percentage of about $10 \%$ occurring in women $[17,18]$. Recently, possibly due to the influence of many of the habits of men which are harmful for the health, there has been a significant increase in the incidence of this disease in females. Furthermore, the tongue consists the most common location in oral cancer, surpassing lip cancer in frequency. The tongue cancer due to anatomical particularities, behaves in treatment in a special way $[19,20]$. This imposes the approach of the disease with great prudence and responsibility. The tongue is embryologically derived from the outer skin of the primordial mouth (oral vagina), the oral pharyngeal endoderm, the pharyngeal mesoderm and the occipital tubes. Moreover, the upper surface of the tongue is divided into two parts: the anterior and the posterior, in terms of the mucosa that covers them, their innervation

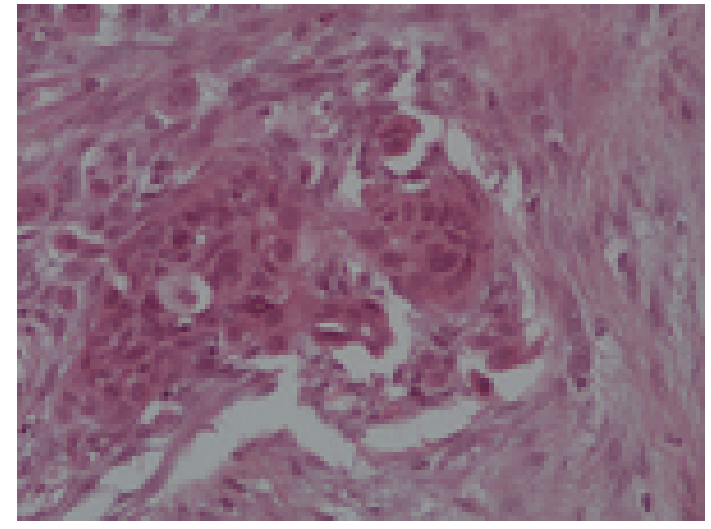

Figure 4. Squamous carcinoma. Pronounced cytonuclear atypia and fetal origin [17-20]. The mucous membrane of the tongue consists of epithelium, non-keratinized squamous polyp, chorea and glands. Furthermore, the mucosa that covers the lower surface of the tongue is smooth, without nipples, thin and loosely attached to the underlying tissues. On the contrary, the mucosa covering the back of the tongue is thick, has nipples, is firmly attached to the underlying tissues and has an irregular surface. The mucosa of the oral cavity of the tongue, in addition to the secondary nipples of the dermis, also has the long or prominent nipples, which are created by the care of the dermis covered by epithelium. The mucosa of the pharyngeal tongue has no nipples, but contains abundant lymphadenoid tissue in the form of lymph nodes [17-20].

An increasing rate of experimental data shows that miRNAs play an important role in regulating cell proliferation and apoptosis, promoting the development of squamous cell carcinoma of the oral epithelium. The miRNAs are thought to regulate the expression of more than onethird of the genes in the human genome, which are encoded and carry information on protein synthesis [21,22]. There are some miRNAs molecules that have been described and appear to be involved in the pathogenesis of squamous cell carcinoma of the tongue [23-25]. These molecules are miR-184, miR-24, miR-7, miR-222 \& miR-21, which has been proposed as an independent prognostic indicator of poor prognosis in patients with squamous cell carcinoma of the tongue, miR133a \& miR -133b, miR-200b \& miR-15b, miR-214 \& miR-23a], miR140-5p, miR-181a, miR-25-3p], miR-195, miR-138. In particular, tongue cancer has been found to be associated with low levels of tropomyosin 1 (TPM1) and PTEN (phosphatase tensin homolog) and inhibit cell apoptosis [23-25]. Disabling miR-21 with anti-miR-21 promotes apoptosis and suppresses cancer growth MiR-184, whose levels increase in tongue cancer, acts as an antidepressant and as a regulator of cell proliferation. Inhibition of miR-184 reduces cell proliferation and promotes cell apoptosis. The literature review shows that there are $6 \mathrm{mi}$ RNAs, which showed a significant difference in their expression and which are reported to be directly related to the pathogenesis of tongue cancer [23-25]. These molecules are: miR-7, miR-222, miR-21, miR-15, miR-138, miR-133. In addition to their role in the pathogenesis of the disease, it is reported that these molecules could be used as possible diagnostic and prognostic factors. A large number of mi RNAs have been found to play the role of oncogene or tumor suppressor gene, participating in various biological processes of tongue cancer, such as cell proliferation, cell apoptosis, metastasis, resistance to chemotherapy. MicroRNAs (miRNAs) are a group of RNA molecules, consisting of 18-24 nucleotides that do not carry protein synthesis information, but regulate gene expression at the meta-transcriptional level. They adjust the translation by connecting the bases, which is not perfect [23-25].

They are involved in regulating cellular functions such as the cell cycle, differentiation and apoptosis leading to malignant lesions, such as squamous cell carcinoma of the tongue. According to reports on miRNAs for their participation in the occurrence and progression of cancer in the oral cavity and tongue, they show a significant difference in their expression between cancer and normal cells of the tongue [2325 ]. The change in the expression of miRNAs has been linked to tumor permeability and their ability to metastasize. The leading cause of death in patients with squamous cell carcinoma of the tongue remains the metastases. Tongue carcinoma usually metastasizes to the cervix early and often. When the lesion is located on one side of the lip, the metastases may appear unilaterally or bilaterally. Most commonly, cervical metastases occur unilaterally. Bilateral metastases are observed when the unilateral flow of the lymph is obstructed by the tumor, surgery or fibrosis that occurs after radiotherapy. Subsequent, after any treatment, 
Tsikouras P (2020) Tongue cancer and pregnancy: Report of two cases in association with HPV infection and literature review. Is HPV vaccination necessary to prevent of tongue cancer?

heterogeneous metastasis may mean either that the metastases preexisted but were not clinically and imaginatively apparent, or that they occurred during or after treatment. Submandibular lymph nodes are mostly not affected, however they are always included in the cervical cleansing. [23-25].

Tumors on the lateral lips of the tongue metastasize to the submandibular lymph nodes or directly to the deep sphincters. Tumors of the posterior third of the tongue give metastases directly to the deep jugular lymph nodes. In the rare cases of localization in the midline of the tongue, metastases are expected bilaterally, although very often they remain unilateral. Tobacco alone is a risk factor for tongue cancer, and the combination of tobacco and alcohol abuse has been shown to cause carcinogenesis in the tongue.

Human papillomavirus (HPV) has an important role in tongue cancer with about 7-fold increasing frequency, especially in the base of tongue according to few publishing reports which have limited conclusions value due to including only a small number of participants. The HPV genome consists of three regions: early (E), late (L) and one long control region (LCR). The early region accounts for more than $50 \%$ of the viral genome and has six open reading frames that encode non-structural proteins E1, E2, E4, E5, E6 and E7. Proteins E5, E6, and E7, encoded by HR-HPV (High Risk HPV), exhibit oncogenic activity as they inhibit the function of tumor suppressor proteins, ensuring the continued division of the infected cell. The late region accounts for almost $40 \%$ of the viral genome and is responsible for encoding major (L1) and minor (L2) capsule protein. The distinction of genes early and late is related to the phase of the life cycle of the virus in which they are expressed. Family proteins includes the $\mathrm{p} 16^{\mathrm{INK} 4 \mathrm{a}}, \mathrm{p} 21^{\mathrm{CIP} 1}, \mathrm{p} 27^{\mathrm{KIP} 1}$, and associated proteins $\mathrm{p} 15^{\mathrm{INK} 4 \mathrm{~b}}, \mathrm{p} 18^{\mathrm{INK} 4 \mathrm{c}}, \mathrm{p} 19^{\mathrm{INK} 4 \mathrm{~d}}$ and $\mathrm{p} 57^{\mathrm{KIP} 2}$ and these proteins potentially act as tumor suppressors while their inactivation corresponds with human carcinogenesis [26-28]. The mechanism for causing carcinogenesis is initially the entry of the genetic material of the virus into the host (human) genome and overexpression of the E6 and E7 proteins. By altering the host gene genome, these proteins disrupt the function of $\mathrm{p} 53$ and $\mathrm{pRb}$ tumor suppressor genes and alter the activity of various other proteins involved in carcinogenesis HPV DNA detection based on PCR using the general primer pairs GP5+/6+ and CPI/IIG confirm the presence of HPV-16 and HPV -33 DNA. The vast majority of HPV positive cancers are associated to expression of HPV -16, E6 and E7 RNA [26-28].

In our both described cases based on PCR mass spectrometry assay also $16^{\text {INK4a }}$ expression, which is a sensitive surrogate marker for transcription activity of HPV high risk subtypes was confirmed positive in the tumor specimen examinations for HPV subtype. According to their personal history was noted only nicotine abuse in both women without vaccination for HPV [26-28].

Although exist no evidence that pregnancy has negative effect to outcome of tongue cancer, however the coexistence of pregnancy and tongue cancer led to compromising treatment choice to provide optimum treatment for the pregnant woman without risk for the fetus. The management of tongue cancer is still controversial and the difficult decision of the optimal treatment of tongue cancer during pregnancy should be depending on tumor evaluations findings, trimester and course of pregnancy which the cancer occurred and the opinion of the pregnant woman and her family. It is of great importance the treatment choice to have advantages for woman life quality without risks for maternal life and none disadvantages for fetus safety. The treatment choice should be consider tumor, maternal and fetal data like tumor stage, histological type, fetal specific factors, pregnancy week, fetal growth, expected weight at birth, existing comorbidities. These aspects have great influence to interrupt or to continue the ongoing pregnancy $[29,30]$. The majority of the oral facial maxilla surgeons recommend in early stages as gold standard initial management as following: surgical treatment including primary tumor radical neck lymph nodes dissection due to existing of occult metastases also in early stages 20 $30 \%$ and subsequent external radiotherapy especially in multiple nodal metastasis or extra capsular tumor spread. Depending on increasing of clotting factors during pregnancy and subsequently increasing risk of thromboembolic diseases and anastomotic thrombosis is recommended for prevention the administration of low molecular weight heparin preoperatively. This protocol strategy is also indicated in the puerperal time. Radiotherapy alone is associated to poor prognosis due to side effects like osteoradionecrosis of mandible, development of childhood cancer in fetus and other primary tumors. However is indicated only in cases which the surgery procedure is contraindicated like in existing of severe concomitant diseases $[29,30]$.

In those cases where pregnancy in the first trimester is complicated by tongue cancer, the possibility of termination of pregnancy is an option. Complete information that includes the potential benefits and disadvantages for the mother and the newborn from continuing or terminating the pregnancy, from the postponement of the start of treatment, the action and side effects of the treatment, the time marks of the treatment, the issues that may to arise from possible future fertility, the time frame for the next attempt at pregnancy, should be given to the patient. In general, surgery is the cornerstone in the treatment of tongue cancer.

In all other cases, radiotherapy should be postponed until delivery. However, if necessary, in general, those patients who received radiation in the pelvic area are at greater risk for asymmetric fetal development, placental implantation disorders and premature birth. Possible penetration beyond the endometrium and placental insufficiency can be assessed by ultrasound in the end of the second and in the third trimester of pregnancy. According to previously publishing reports, radiotherapy is associated to side effects fetal malformations growth retardation and genetic effects. Only dose below $50 \mathrm{mg}$ is possible safe for the fetus. Although there are only few existing reports with oral cavity tumors and pregnancy, treatment of tongue cancer with radiotherapy is safe during the pregnancy. However is of great importance to stop radiation therapy two or three weeks before labor.

Preoperative and systemic chemotherapy are contraindicated in the first trimester of pregnancy. The period of embryogenesis and organogenesis is important and makes the fetus particularly vulnerable to the effects of exogenous chemicals. The start of chemotherapy in the second trimester gives the mother the advantage of survival and should be offered as an option. The use of the appropriate substances of systemic chemotherapy is very important. In summary, anthracyclines are used with relative safety and fears of dose-dependent cardiomyopathy are not verified by a small statistical study. Reports of fetal safety from the use of pads are encouraging in the second and third trimesters of pregnancy. Fluorouracil is also used. Of course, the use of methotrexate in pregnancy as an abortion drug is contraindicated in all trimesters of pregnancy, due to the miscarriages it causes and its teratogenic potential, while platinum derivatives (Cisplatin and Carboplatin) in combination with paclitaxel and 5-fluoruracil are used. The first diagnosis of tongue cancer in the third trimester is due to the need to keep two organisms healthy at the same time, but with different priorities in the definition of health, without disadvantages to maternal health and fetal or neonatal outcome $[29,30]$. 

prevent of tongue cancer?

During pregnancy there is clear and no doubt that existing fetal risks due to treatment either surgical or oncological independent from pregnancy trimester being on the administrated drugs, anesthesia and hypoxaemia. In first trimester, the most serious problems are teratogenic effects of the administrated drugs and spontaneous abortion. The anesthetic drugs may be negatively influence cell mitosis, DNA synthesis and fetal hypoxaemia, if the surgery intervention has duration of prolonged time. About $2 \%$ of women underwent every year in surgical procedures every year in Europe for none obstetrics reasons. The most frequent indications are acute abdominal pain trauma, inflammation and malignancy. The time in the second trimester is relatively the safest period in which the risk for fetal malformation is low. The fetus gains daily benefits from the prolongation of its hosting in the endometrial cavity and from its non-contact with chemotherapeutic agents. On the other hand, the mother's body urgently needs to get rid of the malignancy and be immediately protected from future risks from the timely start of additional treatment. The counseling and treatment team must provide the mother and father with all available information to make the right decision. According to the majority of the obstetricians is recommended to choose as ideal labortime 34 week and also breastfeeding is general recommended. When the pregnancy is full-term or the fetal maturity is evidenced, by examining the tongue and oral cavity with or without the use of cortisone for pulmonary maturation then the pregnancy is terminated and the mother's treatment is followed $[29,30]$.

The problem is detected when tongue cancer is diagnosed in the early third trimester and before the 34th week of pregnancy, because then it must be decided whether the immediate termination with delivery or cesarean section, or the postponement of the mother's treatment until the fetus matures, or the immediate initiation of treatment for tongue cancer. The treatment options are the same as those of the second trimester of pregnancy. During surgery in the third trimester of pregnancy, it is advisable to perform cardiotocographic examination, while intraoperative and/or postoperative use is useful in the administration of tocolytic drugs due to prevention of stress or suppression of myometrial activity. It should be noted that in case chemotherapy has already started during pregnancy, the last chemotherapy regimen should be at least two weeks before the childbirth, in order to have both the uterine bone marrow recovered and to avoid neutropenia, thrombocytopenia problems, possible bleeding during childbirth or subsequent sepsis.

Pregnant women diagnosed with metastatic tongue cancer are a separate population and the management of these patients is special. Despite the inalienable right of every woman to motherhood, however, the logic of Evidence Based Medicine must lead the physician to a more objective approach to the patient $[29,30]$.

The therapeutic goal in patients with metastatic disease is to prolong survival, relieve the possible symptoms of metastatic disease, and maintain or improve quality of life when possible.

The average survival of these patients does not exceed two years and ranges from a few months to several years. Pregnancies generally in the first and second trimesters are likely to be easier to stop, while those in the third trimester are more likely to give birth faster. The gray zone of pregnancies at the end of the second and beginning of the third trimester is always a matter for different decisions. Of course, the above does not always coincide with the desire of the mother, who precedes the medical services. Sometimes the inner strength of motherhood and the optimism gained from it leave medical thought helpless.
Tongue cancer as a pathogen does not adversely affect pregnancy. Cases of cancer metastasis in pregnancy are generally described in cancer cases, but are rare and occur mainly in the case of metastatic melanoma and lymphoma. Nutrition remains unaffected unless the stage of the tongue cancer is advanced $[29,30]$.

The energy needs of metastatic foci deprive maternal blood of nutrients and oxygen, while the anorexia and malnutrition of the mother, which often coexists, exacerbates the condition. Of course, on liver and lung foci, depending on their severity, the exchange of substances between maternal and fetal blood is also affected. However, pregnancy can continue to be unaffected by tongue cancer and become complete in the absence of the disease. Pregnancy can be completed with either a normal birth or a caesarean section. When it is necessary to induce labor then this is possible with the use of the same means as in any pregnancy, i.e. with the use of prostaglandins, an attempt to rupture the follicle and oxytocin.

Breastfeeding can begin fourteen days after the end of the last chemotherapy or radiotherapy regimen, so that enough time has elapsed to clear breast milk.

In the meantime, the mother who wants to maintain the milk supply can pump the milk by mechanical means and discard the produced milk. If chemotherapy is started again, then breastfeeding should be stopped again. As for the complications of an impending pregnancy that one expects in a cancer patient, they mainly concern higher abortion rates, low birth weight and premature infants $[29,30]$.

Nevertheless, the relevant knowledge is based on retrospective studies and lacks statistical significance. As for the effect of chemotherapy in a future pregnancy, it does not appear to increase the risk of miscarriage, affect uterine function or restrict fetal development. As for the effect of radiotherapy on a possible pregnancy, this was associated with miscarriage, premature birth, low birth weight, asymmetric fetal development and penetrating placenta. A possible interpretation of these results is the effect that radiation can have on vascularity and the failure of vascular support in implantation and growth of the fetus in the endometrium. It is also possible that the elasticity of the uterus is lost due to fibrosis and the endometrium is injured due to the effect of radiation.

According to the above data, it would be possible to make some additional recommendations for better monitoring of a pregnant woman with a history of cancer at a younger age.

Additional techniques that can be used for clarification are color Doppler ultrasound and MRI of the uterus. Repeated ultrasound examination every 4 or 6 weeks after the 22nd week is recommended to assess fetal development. Weekly Non Stress Cardiotocography Test (NST) after the $32^{\text {nd }}$ week of pregnancy is recommended for those pregnant women who underwent abdominal irradiation before menstruation because they have an increased risk of endometrial death.

We present 2 cases with tongue cancer during pregnancies which have treated according to the recommend treatment strategies in previously published cases Table 1 which include the majority of articles identified in our research in Pubmed library using keywords tongue cancer and pregnancy in association to most notable clinicopathological parameters. In none of the reported cases was investigated the assessment of HPV status. According to our opinion based on this mentioned finding we recommend to all women until 55 years to participate in HPV screening especially before the beginning of pregnancy 
Tsikouras P (2020) Tongue cancer and pregnancy: Report of two cases in association with HPV infection and literature review. Is HPV vaccination necessary to prevent of tongue cancer?

Table 1. Report of previous published tongue cancers cases associated to pregnancy

\begin{tabular}{|c|c|c|c|c|c|c|}
\hline Author & AGE & WEEK & TREATMENT & STAGE & LABOR & RECURRENCE \\
\hline Layton. et al. 1992 & $27 \mathrm{j}$ & $23 \mathrm{w}$ & $\begin{array}{c}\text { SURGERY } \\
\text { RADIOTHERAPY }\end{array}$ & T2NOMO- & $36 \mathrm{~W}$ VAG & $\begin{array}{c}\text { RECURRECNCE } 3 \text { MONTHS } \\
\text { LATER }\end{array}$ \\
\hline $\begin{array}{l}\text { Shibuya et al. } 1987 \\
\text { TWO CASES }\end{array}$ & $\begin{array}{l}29 \mathrm{~J} \\
31 \mathrm{~J}\end{array}$ & $\begin{array}{l}26 \mathrm{~W} \\
28 \mathrm{~W}\end{array}$ & $\begin{array}{c}\text { SURGERY } \\
\text { RADIOTHERAPY }\end{array}$ & $\begin{array}{l}\text { T1NOMO } \\
\text { T1N1MO }\end{array}$ & $\begin{array}{l}37 \mathrm{CS} \\
38 \mathrm{CS}\end{array}$ & $\begin{array}{c}\text { NO RECURRECNCE } \\
\text { RECURRECNCE } 4 \text { YEARS } \\
\text { LATER }\end{array}$ \\
\hline Lasaridis et al. 1996 & $32 \mathrm{j}$ & $25 w$ & $\begin{array}{c}\text { SURGERY } \\
\text { RADIOTHERAPY }\end{array}$ & T2, N1, MO III & $38 \mathrm{VAG}$ & NO RECURRECNCE \\
\hline Lloyd et al. 2003 & $36 \mathrm{~J}$ & $15 \mathrm{~W}$ & $\begin{array}{c}\text { TSURGERY } \\
\text { RADIOTHERAPY }\end{array}$ & $\mathrm{T} 2 \mathrm{~N} 1 \mathrm{MO}$ & $39 \mathrm{VAG}$ & $\begin{array}{c}\text { RECURRECNCE } 6 \text { MONTHS } \\
\text { LATER }\end{array}$ \\
\hline $\begin{array}{l}\text { Yokoshima et al. } 2012 \\
\text { THREE CASES }\end{array}$ & $\begin{array}{l}29 \\
29 \\
26\end{array}$ & $\begin{array}{l}30 \mathrm{~W} \\
20 \mathrm{~W} \\
27 \mathrm{~W}\end{array}$ & $\begin{array}{c}\text { SURGERY } \\
\text { RADIOTHERAPY }\end{array}$ & $\begin{array}{l}\text { T3NOMO T2NOMO } \\
\text { T1N0MO }\end{array}$ & $\begin{array}{l}38 \mathrm{WAG} \\
37 \mathrm{VAG} \\
38 \mathrm{VAG}\end{array}$ & $\begin{array}{c}\text { NO RECURRENCE } \\
\text { DIED, RECURRENCE, } 2 \text { YEARS } \\
\text { NO RECURRENCE }\end{array}$ \\
\hline $\begin{array}{l}\text { Tagliabue } \text { et al. } 2016 \\
\text { SIX CASES }\end{array}$ & $\begin{array}{l}31 \mathrm{~J} \\
35 \mathrm{~J} \\
30 \mathrm{~J} \\
32 \mathrm{~J} \\
37 \mathrm{~J} \\
40 \mathrm{~J}\end{array}$ & $\begin{array}{l}19 \mathrm{~W} \\
26 \mathrm{~W} \\
15 \mathrm{~W} \\
28 \mathrm{~W} \\
31 \mathrm{~W} \\
14 \mathrm{~W}\end{array}$ & $\begin{array}{c}\text { SURGERY } \\
\text { RADIOTHERAPY }\end{array}$ & $\begin{array}{c}\text { T1cN0M0 T1cN0M0 } \\
\text { T1cN0M0 T1cN0M0 } \\
\text { T4N0M0 } \\
\text { T1N0M0 }\end{array}$ & $\begin{array}{l}38 \mathrm{VAG} \\
40 \mathrm{VAG} \\
38 \mathrm{VAG} \\
34 \mathrm{VAG} \\
30 \mathrm{~W} \mathrm{CS} \\
34 \mathrm{~W} \mathrm{CS}\end{array}$ & $\begin{array}{c}\text { NO RECURRENCE } \\
\text { NO RECURRENCE } \\
\text { NO RECURRENCE } \\
\text { NO RECURRENCE } \\
\text { DIED, RECURRENCE, } 2 \text { YEARS } \\
\text { DIED, RECURRENCE, } 1 \text { YEAR }\end{array}$ \\
\hline $\begin{array}{l}\text { Sato et al. } 2019 \\
\text { FOUR CASES }\end{array}$ & $\begin{array}{l}29 \mathrm{~J} \\
32 \mathrm{~J} \\
33 \mathrm{~J} \\
39 \mathrm{~J}\end{array}$ & $\begin{array}{l}16 \mathrm{~W} \\
13 \mathrm{~W} \\
25 \mathrm{~W} \\
17 \mathrm{~W}\end{array}$ & $\begin{array}{c}\text { SURGERY } \\
\text { RADIOTHERAPY }\end{array}$ & $\begin{array}{l}\text { T2N0M0 T2N0M0 } \\
\text { T1N0M0 T0N0M1 }\end{array}$ & $\begin{array}{l}40 \mathrm{VAG} \\
39 \mathrm{VAG} \\
40 \mathrm{VAG} \\
29 \mathrm{~W} \mathrm{CS}\end{array}$ & $\begin{array}{l}\text { NO RECURRENCE } \\
\text { NO RECURRENCE } \\
\text { NO RECURRENCE } \\
\text { DIED, RECURRENCE, } 10 \\
\text { MONTHS }\end{array}$ \\
\hline Shah et al. 2012 & $28 \mathrm{~J}$ & $37 \mathrm{~W}$ & SURGERY & T1N0M0 & $37 \mathrm{~W} \mathrm{CS}$ & NO RECURRENCE \\
\hline Unsworth et al. 2013 & $29 \mathrm{~J}$ & $12 \mathrm{~W}$ & $\begin{array}{c}\text { SURGERY } \\
\text { RADIOTHERAPY }\end{array}$ & $\begin{array}{l}\text { T2N0M0 } \\
\text { SLE }\end{array}$ & $36 \mathrm{~W}$ VAG & NO RECURRENCE \\
\hline $\begin{array}{l}\text { Gziri et al. } 2011 \\
17 \text { CASES }\end{array}$ & $\begin{array}{l}28 \mathrm{~J} \\
26 \mathrm{~J} \\
29 \mathrm{~J} \\
34 \mathrm{~J} \\
36 \mathrm{~J} \\
32 \mathrm{~J} \\
33 \mathrm{~J} \\
36 \mathrm{~J} \\
37 \mathrm{~J} \\
38 \mathrm{~J} \\
39 \mathrm{~J} \\
34 \mathrm{~J} \\
35 \mathrm{~J} \\
36 \mathrm{~J} \\
37 \mathrm{~J} \\
38 \mathrm{~J} \\
35 \mathrm{~J}\end{array}$ & $\begin{array}{l}25 \mathrm{~W} \\
14 \mathrm{~W} \\
31 \mathrm{~W} \\
25 \mathrm{~W} \\
28 \mathrm{~W} \\
26 \mathrm{~W} \\
23 \mathrm{~W} \\
16 \mathrm{~W} \\
24 \mathrm{~W} \\
9 \mathrm{~W} \\
27 \mathrm{~W} \\
12 \mathrm{~W} \\
11 \mathrm{~W} \\
24 \mathrm{~W} \\
10 \mathrm{~W} \\
10 \mathrm{~W} \\
5 \mathrm{~W}\end{array}$ & $\begin{array}{c}\text { SURGERY } \\
\text { RADIOTHERAPY } \\
\text { SURGERY } \\
\text { RADIOTHERAPY } \\
\text { SURGERY } \\
\text { RADIOTHERAPY } \\
\text { SURGERY } \\
\text { RADIOTHERAPY } \\
\text { SURGERY } \\
\text { RADIOTHERAPY } \\
\text { NONE } \\
\text { NONE SURGERY } \\
\\
\text { RADIOTHERAPY } \\
\text { SURGERY } \\
\text { RADIOTHERAPY }\end{array}$ & $\begin{array}{c}\text { T2N1M0 } \\
\text { T2N1M0 } \\
\text { T2N0M0 } \\
\text { T2N0M0 } \\
\text { T2N0M0 } \\
\text { T2N0M0 } \\
\text { T2N0M0 } \\
\text { T2N2BM0 } \\
\text { T4N1M0 } \\
\text { T4N2cM0 } \\
\text { LOCAL REC } \\
\text { T2N1M0 }\end{array}$ & $\begin{array}{l}36 \mathrm{VAG} \\
37 \mathrm{VAG} \\
32 \mathrm{~W} \mathrm{CS} \\
34 \mathrm{~W} \mathrm{CS} \\
32 \mathrm{~W} \mathrm{CS} \\
36 \mathrm{~W} \mathrm{VAG} \\
36 \mathrm{VAG} \\
27 \mathrm{VAG} \\
38 \mathrm{VAG} \\
27 \mathrm{CS} \\
38 \mathrm{VAG} \\
38 \mathrm{VAG} \\
36 \mathrm{VAG} \\
38 \mathrm{VAG} \\
40 \mathrm{VAG}\end{array}$ & $\begin{array}{c}\text { NO RECURRENCE } \\
\text { RECURRENCE } \\
\text { NO RECURRENCE } \\
\text { DIED } \\
\text { NO RECURREENCE } \\
\text { NO RECURRENCE } \\
\text { RECURRENCE } \\
\text { NO RECURRENCE } \\
\text { DIED } \\
\text { NO RECURRENCE } \\
\text { RECURRENCE } \\
\text { NO RECURRENCE } \\
\text { NO RECURRENCE } \\
\text { NO RECURRENCE } \\
\text { NO RECURRENCE }\end{array}$ \\
\hline $\begin{array}{c}\text { Eliassen } \text { et al. } 2013 \\
4 \text { CASES }\end{array}$ & $\begin{array}{l}26 \mathrm{~J} \\
33 \mathrm{~J} \\
30 \mathrm{~J} \\
37 \mathrm{~J}\end{array}$ & $\begin{array}{l}25 \mathrm{~W} \\
26 \mathrm{~W} \\
28 \mathrm{~W} \\
26 \mathrm{~W}\end{array}$ & $\begin{array}{c}\text { SURGERY } \\
\text { RADIOTHERAPY } \\
\text { SURGERY, NO RADIATIO } \\
\text { SURGERY, RADIATIO }\end{array}$ & $\begin{array}{l}\text { T4aN2bM0 } \\
\text { T2N2bM0 } \\
\text { T2N0M0 } \\
\text { T4An2bM0 }\end{array}$ & $\begin{array}{l}36 \mathrm{CS} \\
37 \mathrm{CS} \\
36 \mathrm{VAG}\end{array}$ & $\begin{array}{c}\text { LUNG RECURREENCE AFTER } \\
1 \text { YEAR } \\
\text { NO RECURRENCE } \\
\text { RECURRENCE AFTER } 1 \text { YEAR } \\
\text { NO RECURRENCE } \\
\text { ALL FOUR CASES WERE } \\
\text { POSITIVE BY p16 } 6^{\text {INK4a }} \text { sensitive } \\
\text { surrogate marker }\end{array}$ \\
\hline Murphy J et al. 2016 & $38 \mathrm{j}$ & $14 w$ & SURGERY, RADIATIO & $\mathrm{T} 2 \mathrm{~N} 1 \mathrm{M} 0$ & $38 \mathrm{VAG}$ & NO RECURRENCE \\
\hline $\begin{array}{l}\text { Chow et al. } 2008 \\
2 \text { CASES }\end{array}$ & $\begin{array}{l}34 \mathrm{~J} \\
36 \mathrm{~J}\end{array}$ & $\begin{array}{l}29 \mathrm{~W} \\
26 \mathrm{~W}\end{array}$ & SURGERY, RADIATIO & T2N0M0 & $\begin{array}{l}37 \mathrm{VAG} \\
38 \mathrm{VAG}\end{array}$ & NO RECURRENCE \\
\hline Tapisiz et al. 2007 & $18 \mathrm{~J}$ & $31 \mathrm{~W}$ & SURGERY, CHEMOTHERAPY & T2N1M0 & $32 \mathrm{~W} \mathrm{CS}$ & NO RECURRENCE \\
\hline
\end{tabular}


Tsikouras P (2020) Tongue cancer and pregnancy: Report of two cases in association with HPV infection and literature review. Is HPV vaccination necessary to prevent of tongue cancer?

\begin{tabular}{|c|c|c|c|c|c|c|}
\hline $\begin{array}{l}\text { Letter to Editor, Oral } \\
\text { Oncology47(2011)924-926 }\end{array}$ & $25 \mathrm{~J}$ & $30 \mathrm{~W}$ & SURGERY, RADIATIO & T3N1M0 & $30 \mathrm{CS}$ & RECURRENCE AFTER 1 YEAR \\
\hline $\begin{array}{l}\text { Atabo et al. } 2006 \\
\text { 6 CASES }\end{array}$ & $\begin{array}{l}31 \mathrm{~J} \\
34 \mathrm{~J} \\
24 \mathrm{~J} \\
20 \mathrm{~J} \\
26 \mathrm{~J} \\
28 \mathrm{~J}\end{array}$ & $\begin{array}{l}17 \mathrm{~W} \\
24 \mathrm{~W} \\
25 \mathrm{~W} \\
26 \mathrm{~W} \\
27 \mathrm{~W} \\
26 \mathrm{~W}\end{array}$ & SURGERY, RADIATIO & $\begin{array}{c}\text { T1N0M0 } \\
\text { T1N0M0 } \\
\text { T2N0M0 } \\
\text { T1N0M0 } \\
\text { T1N0M0 } \\
\text { T2N2bM0 }\end{array}$ & $\begin{array}{c}38 \mathrm{vag} \\
\text { UNKNOWN } \\
34 \mathrm{CS} \\
24 \text { ABORTION } \\
34 \text { CS } \\
27 \mathrm{CS}\end{array}$ & $\begin{array}{c}\text { NO RECURRENCE } \\
\text { NO RECURRENCE } \\
\text { NO RECURRENCE } \\
\text { NO RECURRENCE } \\
\text { NO RECURRENCE } \\
\text { DIED }\end{array}$ \\
\hline
\end{tabular}

After consideration with the pregnant women in both cases we have terminated the pregnancies and continued the treatment during the puerperal time. Although no existing clear guidelines of tongue cancer during pregnancy, however in the previously published studies were confirmed very notable findings which are very useful for clinical decisions, but there are more areas like HPV subtypes association to head neck oral cancers which needed more scientific research.

\section{Conclusions}

Further research for this very important scientific disease area is necessary and the purpose of the present study by reporting two cases of pregnant women suffering from tongue cancer during pregnancy is to contribute of experience in the treatment of tongue cancer. The lack of systematic randomized prospective studies and the difficulties in carrying them out in general, led to follow the useful conclusions of retrospective studies, which however have a lot of limitations, but offer scientific stimulus for future scientific studies to be performed, in order to establish treatment protocols. Future research into malignancy is focused on personalizing treatment and we recommend based on our experience the performance of prophylactic HPV vaccination in all people independent from HPV screening and especially in women which is desired family planning and pregnancy.

The decoding of the human genome has significantly expanded our knowledge of the genetic status of human tissues and is constantly paving the way for relevant research. Monitoring of pregnant women has now improved and medical practice is constantly gaining new research. When it is decided to continue and finish, then the newborn should be used as an additional motivation for the mother to fight evil and act as a distraction, shifting the focus of the mother's interest from the fear of death to the joy of life.

\section{References}

1. Layton SA, Rintoul M, Avery BS (1992) Oral carcinoma in pregnancy. Br J Oral Maxillofac Surg 30: 161-164.

2. Mhallem Gziri M, Han SN, Van Calsteren K, Heyns L, Delaere P, et al. (2013) Tongue cancers during pregnancy: Case reports and review of literature. Head Neck 35: 102108

3. Chow VLY, Chan JYW, Ng RQM, Wei WI (2008) Management of head and neck tumours during pregnancy: case report and literature review. Asian J Surg 31: 199-203. [Crossref]

4. Sato K, Shimamoto H, Mochizuki Y, Hirai H, Tomioka H, et al. (2019) Treatment of oral cancers during pregnancy: a case-based discussion. J Otolaryngol Head Neck Surg 48: 9 .

5. Shibuya H, Saiot M, Horiuchi JI, Suzuki S (1987) Treatment of malignant head and neck tumors during pregnancy--a report of 3 cases. Acta Oncol 26: 237-238.

6. Lloyd CJ, Paley MD, Penfold CN, Varadarajan V, Tehan B (2003) Microvascular free tissue transfer in the management of squamous cell carcinoma of the tongue during pregnancy. Br J Oral Maxillofac Surg 41: 109-111.

7. Lasaridis N, Tilaveridis I, Karakasis D (1996) Management of a carcinoma of the tongue during pregnancy: report of case. J Oral Maxillofac Surg 54: 221-224.
8. Attner P, Du J, Näsman A, Hammarstedt L, Ramqvist T, et al. (2010) The role of human papillomavirus in the increased incidence of base of tongue cancer. Int J Cancer 15: 2879-2884.

9. Yokoshima K, Nakamizo M, Sakanushi A, Ozu R, Yamaguchi S, et al. (2012) Surgical management of tongue cancer during pregnancy. Auris Nasus Larynx 4: 428-430.

10. Tagliabue M, Elrefaey SH, Peccatori F, Favia G, Navach V (2016) Luca calabrese tongue cancer during pregnancy: Surgery and more, a multidisciplinary challenge. Crit Rev Oncol Hematol 98: 1-11. [Crossref]

11. Ganly I, Patel S, Shah J (2012) Early stage squamous cell cancer of the oral tongue-clinicopathologic features affecting outcome. Cancer 118: 101-111.

12. Unsworth JD, Baldwin A, Byrd L (2013) Systemic lupus erythematosus, pregnancy and carcinoma of the tongue. BMJ Case Rep 31.

13. Eliassen AM, Hauff SJ, Tang AL, Thomas DH, McHugh JB (2014) Head and neck squamous cell carcinoma in pregnant women. Head Neck 35: 335-342.

14. Murphy J, Berman DR, Edwards SP, Prisciandaro J, Eisbruch A (2016) Ward squamous cell carcinoma of the tongue during pregnancy: A case report and review of the literature. J Oral Maxillofac Surg 74: 2557-2566.

15. Atabo A, Bradley PJ (2008) Management principles of head and neck cancers during pregnancy: A review and case series. Oral Oncol 44: 236-241.

16. Shukun Shen, Liqun Xu, Xuelai Yin, Xindong Fan, Lin Zhang (2011) A case of a squamous cell carcinoma of the tongue during pregnancy: Letters to the Editor. Oral Oncology 47: 9.

17. Najeeb T (2006) Clinicopathological presentation of tongue cancers and early cancer treatment. J Coll Physicians Surg Pak 16: 179-82. [Crossref]

18. Iype EM, Pandey M, Mathew A, Thomas G, Nair MK (2004) Squamous cell cancer of the buccal mucosa in young adults. Br J Oral Maxillofac Surg 42: 185-189.

19. Chitapanarux I, Lorvidhaya V, Sittitrai P, Pattarasakulchai T, Tharavichitkul E, et al (2006) Oral cavity cancers at a young age: analysis of patient, tumor and treatment characteristics in Chiang Mai University Hospital. Oral Oncol 42: 83-88.

20. Tapisiz OM, Gungor T, Ustunyurt E, Ozdal B, Bilge U (2008) An unusual case of lingual alveolar soft part sarcoma during pregnancy Taiwan. J Obstet Gynecol 47: 212-214.

21. Gomes CC, Gomez RS (2008) MicroRNA and oral cancer: future perspectives. Oral Oncol 44: 910-914.

22. Chang KW, Kao SY, Wu YH, Tsai MM, Tu HF (2013) Passenger strand miRNA miR$31^{*}$ regulates the phenotypes of oral cancer cells by targeting RhoA. Oral Oncol 49 27-33.

23. Wu BH, Xiong XP, Jia J, Zhang WF (2011) MicroRNAs: new actors in the oral cancer scene. Oral Oncol 47: 314-319.

24. Chawla JP, Iyer N, Soodan KS, Sharma A, Khurana SK (2015) Role of miRNA in cancer diagnosis, prognosis, therapy and regulation of its expression by Epstein-Barr virus and human papillomaviruses: With special reference to oral cancer. Oral Oncol 51: 731-737.

25. Gorenchtein M, Poh CF, Saini R, Garnis C (2012) MicroRNAs in an oral cancer context - from basic biology to clinical utility. J Dent Res 91: 440-446.

26. Chocolatewala NM, Chaturvedi P (2009) Role of human papilloma virus in the oral carcinogenesis: an Indian perspective. $J$ Cancer Res Ther 5: 71-77.

27. Dalakoti P, Ramaswamy B, Bhandarkar AM, Nayak DR, Sabeena S (2019) Prevalence of HPV in oral squamous cell carcinoma in south west India. Indian J Otolaryngol Head Neck Surg 71: 657-664.

28. Sabu A, Mouli NVR, Tejaswini N, Rohit V, Nishitha G (2019) Human papillomaviru detection in oropharyngeal squamous cell carcinoma using p16 Immunohistochemistry. Int J Appl Basic Med Res 9: 212-216. 
Tsikouras P (2020) Tongue cancer and pregnancy: Report of two cases in association with HPV infection and literature review. Is HPV vaccination necessary to prevent of tongue cancer?

29. Tagliabue M, Elrefaey SH, Peccatori F, Favia G, Navach V (2016) Tongue cancer during pregnancy: Surgery and more, a multidisciplinary challenge. Crit Rev Oncol Hematol 98: 1-11.
30. Chow VL, Chan JY, Ng RW, Wei WI (2008) Management of head and neck tumours during pregnancy: case report and literature review. Asian J Surg 31: 199-203.

Copyright: $(02020$ Tsikouras P. This is an open-access article distributed under the terms of the Creative Commons Attribution License, which permits unrestricted use, distribution, and reproduction in any medium, provided the original author and source are credited. 